\title{
Systematic Review \\ Efficacy of Teduglutide for Parenteral Support Reduction in Patients with Short Bowel Syndrome: A Systematic Review and Meta-Analysis
}

\author{
Fabio Bioletto ${ }^{1}$, , Chiara D'Eusebio ${ }^{1}$, Fabio Dario Merlo ${ }^{2}$ (D), Umberto Aimasso ${ }^{2}$, Marta Ossola ${ }^{2}$, \\ Marianna Pellegrini ${ }^{1}$ D, , Valentina Ponzo ${ }^{1}$, Alessia Chiarotto ${ }^{2}$, Antonella De Francesco ${ }^{2}$, Ezio Ghigo ${ }^{1}$ \\ and Simona Bo ${ }^{1, * \mathbb{D}}$
}

\section{check for}

updates

Citation: Bioletto, F.; D'Eusebio, C.; Merlo, F.D.; Aimasso, U.; Ossola, M.; Pellegrini, M.; Ponzo, V.; Chiarotto, A.; De Francesco, A.; Ghigo, E.; et al. Efficacy of Teduglutide for Parenteral Support Reduction in Patients with Short Bowel Syndrome: A Systematic Review and Meta-Analysis. Nutrients 2022, 14, 796. https://doi.org/ $10.3390 /$ nu14040796

Academic Editor: Jon Marc Rhoads

Received: 16 January 2022

Accepted: 10 February 2022

Published: 14 February 2022

Publisher's Note: MDPI stays neutral with regard to jurisdictional claims in published maps and institutional affiliations.

Copyright: (C) 2022 by the authors. Licensee MDPI, Basel, Switzerland. This article is an open access article distributed under the terms and conditions of the Creative Commons Attribution (CC BY) license (https:// creativecommons.org/licenses/by/ $4.0 /)$.
1 Department of Medical Sciences, University of Turin, 10126 Turin, Italy; fabio.bioletto@unito.it (F.B.); chiara.deusi@gmail.com (C.D.); mariannapellegrini87@gmail.com (M.P.); valentina.ponzo@unito.it (V.P.); ezio.ghigo@unito.it (E.G.)

2 Dietetic Unit, Città della Salute e della Scienza Hospital, 10126 Turin, Italy; fdmerlo@gmail.com (F.D.M.); uaimasso@cittadellasalute.to.it (U.A.); mossola@cittadellasalute.to.it (M.O.); alessia.chiarotto@unito.it (A.C.); defrancesco54anto@gmail.com (A.D.F.)

* Correspondence: simona.bo@unito.it; Tel.: +39-011-633-6036

\begin{abstract}
Teduglutide has been described as an effective treatment for parenteral support (PS) reduction in patients with short bowel syndrome (SBS). However, a quantitative summary of the available evidence is still lacking. PubMed/Medline, EMBASE, Cochrane library, OVID, and CINAHL databases were systematically searched up to July 2021 for studies reporting the rate of response (defined as a $\geq 20 \%$ reduction in PS) to teduglutide among PS-dependent adult patients. The rate of weaning (defined as the achievement of PS independence) was also evaluated as a secondary end-point. Ten studies were finally considered in the meta-analysis. Pooled data show a response rate of $64 \%$ at 6 months, $77 \%$ at 1 year and, $82 \%$ at $\geq 2$ years; on the other hand, the weaning rate could be estimated as $11 \%$ at 6 months, $17 \%$ at 1 year, and $21 \%$ at $\geq 2$ years. The presence of colon in continuity reduced the response rate $(-17 \%, 95 \% \mathrm{CI}:(-31 \%,-3 \%))$, but was associated with a higher weaning rate $(+16 \%, 95 \% \mathrm{CI}:(+6 \%,+25 \%))$. SBS etiology, on the contrary, was not found to be a significant predictor of these outcomes, although a nonsignificant trend towards both higher response rates $(+9 \%, 95 \% \mathrm{CI}:(-8 \%,+27 \%))$ and higher weaning rates $(+7 \%, 95 \% \mathrm{CI}:(-14 \%,+28 \%))$ could be observed in patients with Crohn's disease. This was the first meta-analysis that specifically assessed the efficacy of teduglutide in adult patients with SBS. Our results provide pooled estimates of response and weaning rates over time and identify intestinal anatomy as a significant predictor of these outcomes.
\end{abstract}

Keywords: teduglutide; short bowel syndrome; chronic intestinal failure; parenteral nutrition; parenteral support

\section{Introduction}

Short bowel syndrome (SBS), i.e., the condition following surgical removal of a portion of the small bowel until the intestinal length is shorter than $200 \mathrm{~cm}$, could be caused by different underlying diseases such as mesenteric ischemia, Crohn's disease, radiation enteritis, and surgical complications, among others [1-5]. SBS is the most frequent etiology of chronic intestinal failure (CIF) [1-5]. CIF is defined as the reduction in gut function below the minimum necessary for the absorption of macronutrients and/or water and electrolytes, such that intravenous supplementation is required to maintain health [1-3]; until 1970 [6], CIF was a condition incompatible with life; this is still true in some countries nowadays. Parenteral support (PS), i.e., parenteral nutrition (PN) and/or intravenous fluid administration, revolutionized the prognosis of patients with CIF $[7,8]$. Nevertheless, 
patients with CIF needing chronic PS are still burdened by many complications, such as liver, kidney, and bone disease, acid-base dysregulations, sepsis, catheter thrombosis, and poor quality of life (QoL) [9-15]. Those complications, whose probability is higher as time on PS increases, generate high healthcare costs, which have to be added to those produced by PS itself $[16,17]$.

Teduglutide, an analog of the intestinotrophic hormone glucagon-like-peptide 2 (GLP-2) secreted by the intestinal L-cells, is an effective therapeutic option for patients with SBS-related CIF [18-20]. GLP-2 receptor activation determines, through multiple pathways and mediators, a hypertrophy effect on bowel mucosa, increasing villus height and crypt depth [21,22]; moreover, it also inhibits gastric acid secretions [23], delays gastric emptying [24], stimulates intestinal blood flow [25], and opposes inflammatory insults [26]. Teduglutide treatment, thus, leads to an overall increase in the intestinal absorption capacity, reducing PS needs. Its efficacy in PS reduction was first demonstrated in adult patients $[27,28]$ and, more recently, it has shown effectiveness in children $[29,30]$, with similar results. Weaning off PS, or even just a reduction in volumes and days of weekly infusions, may reduce PS-related healthcare costs and increase the QoL of SBS patients [31]. Teduglutide is, to date, an expensive treatment, but cost effectiveness analyses affirmed that its use could be cost saving in selected subgroups of patients [32]. Previous studies have demonstrated that the teduglutide response in patients with SBS is highly heterogeneous, most likely due to differences in SBS etiology, intestinal anatomy, and PS volume requirements [33-35]. The same holds for the achievement of PS independence, but factors explaining this heterogeneity are less clear, mostly due to the limited number of available patients [36,37]. A better understanding of the predictors of teduglutide efficacy may improve patient management and profiling, as well as optimize the use of healthcare resources [34,35].

The aim of the present systematic review and meta-analysis was to evaluate the efficacy of teduglutide for PS reduction in adult patients with SBS; moreover, its efficacy for PS weaning was assessed. The possible roles of intestinal anatomy and SBS etiology as predictors of these outcomes were also analyzed.

\section{Materials and Methods}

\subsection{Search Strategy and Study Selection}

This study was conducted according to the Preferred Reporting Items for Systematic Reviews and Meta-Analysis (PRISMA) guidelines [38]. The process of literature search and study selection was carried out by three independent reviewers (C.D.E., F.B., V.P.); all disparities were resolved through consensus.

The following electronic databases were queried until 1 July 2021: PubMed/Medline, EMBASE, Cochrane library, OVID, and CINAHL. The search strategy was performed using a combination of relevant database-specific search terms to identify pertinent studies on the efficacy of teduglutide for parenteral support reduction in adult patients with SBS. Both medical subject headings $(\mathrm{MeSH})$ and free-text search terms were employed. The term "teduglutide" was combined with other key words such as short bowel, short gut, intestinal failure, intestinal insufficiency, intestinal deficiency, intestinal growth, intestinal adaptation, parenteral nutrition, parenteral support, complications, cancer, and dysplasia. The full search strategy is presented in Appendix A. No filters were applied for study design, language, or publication date. To expand the search, references of the retrieved articles were also screened for additional studies.

After duplicate removal, all studies found with the aforementioned search were evaluated for inclusion in the meta-analysis, first by title/abstract screening and then by full-text review. We excluded studies from our analysis according to the following exclusion criteria: (a) evaluation of teduglutide treatment efficacy in pediatric patients; (b) evaluation of teduglutide treatment efficacy only at $<24$ weeks; (c) evaluation of teduglutide treatment efficacy at undefined or poorly defined time points; (d) evaluation of <10 PS-dependent patients treated with teduglutide; and (e) unavailability of the primary outcome of interest, 
as defined in the following subsection. Post hoc analyses of included studies were assessed for relevance and employed for data extraction if they contained additional information for the assessment of the outcomes of interest. In case of patient overlap between studies to be pooled in the same analysis, the one with the largest sample size was considered.

\subsection{Outcomes}

The primary outcome of interest was the proportion of patients that achieved PS reduction, defined as a $\geq 20 \%$ reduction in PS volume with respect to baseline; these data will be referred to as "response rate" throughout the rest of the manuscript. The secondary outcome was the proportion of patients that achieved complete PS independence; these data will be referred to as "weaning rate" throughout the rest of the manuscript. Comparisons of response and weaning rates according to intestinal anatomy and SBS etiology were performed based on crude rate differences.

\subsection{Data Extraction}

Three authors (C.D.E., F.B., V.P.) independently examined and extracted data from papers which met the inclusion criteria using prespecified data extraction templates. For each eligible study, the following information was collected: (a) first author and publication year; (b) study design; (c) number of subjects; (d) patients' characteristics in terms of demographic data and SBS-related data; (e) time points at which the efficacy of teduglutide was assessed; (f) observed proportion of patients that achieved $a \geq 20 \%$ reduction in PS volume at each considered time-point (response rate); $(\mathrm{g})$ observed proportion of patients that achieved a complete independence from PS at each considered time-point (weaning rate); (h) stratification of response rate and weaning rate according to intestinal anatomy, if available; and (i) stratification of response rate and weaning rate according to SBS etiology, if available.

\subsection{Risk of Bias Assessment}

The risk of bias was independently assessed for each included study by two authors (F.B., S.B.) using the RoB 2 (Risk of Bias) tool for randomized controlled trials [39] and the ROBINS-I (Risk Of Bias In Non-randomized Studies of Intervention) tool for observational studies [40].

The first tool evaluated five domains, which addressed (a) bias arising from the randomization process, (b) bias due to deviations from intended interventions, (c) bias due to missing outcome data, (d) bias in measurement of the outcome, and (e) bias in selection of the reported result. An additional evaluation of overall risk of bias was also carried out as a summary measure. The options for a domain-level risk-of-bias judgement were 'Low', 'Some concerns' or 'High'. The second tool evaluated seven domains, which addressed (a) bias due to confounding, (b) bias in selection of participants for the study, (c) bias in measurement classification of interventions, (d) bias due to deviations from intended interventions, (e) bias due to missing data, (f) bias in measurement of outcomes, (g) bias in selection of the reported result. An additional evaluation of overall risk of bias was also carried out as a summary measure. The options for a domain-level risk-of-bias judgement were 'Low', 'Moderate', 'Serious' or 'Critical', with an additional option of 'Unknown' if sufficient information for judgement was lacking.

\subsection{Statistical Analysis}

Continuous variables and categorical variables were reported as numbers and percentages, respectively. The proportion of patients that achieved the outcomes of interest was assessed as an absolute rate and compared between groups as a rate difference. A random-effect model with inverse-variance weighting was adopted for statistical pooling of the retrieved data [41]. Higgins $\mathrm{I}^{2}$ statistics and Cochran Q-test were used to assess heterogeneity between studies [42]. Publication bias was quantitatively assessed by Begg's test. 
Statistical analysis was performed using R 4.0.3 (R Core Team, R Foundation for Statistical Computing, Vienna, Austria) and STATA 17 (StataCorp, College Station, TX, USA).

\section{Results}

\subsection{Search Results}

A total of 4906 records were identified in the initial literature search (accounting for possible duplicates within each electronic database if a record was obtained in multiple search strings). Removal of duplicates led to an overall pool of 435 studies. An accurate title or abstract revision was sufficient to exclude 401 articles as not pertinent or not fulfilling our prespecified inclusion or exclusion criteria. The remaining 34 studies were assessed in full-text for eligibility; 10 of them finally met all criteria for being included in the final analysis [27,28,43-50]; 2 additional post hoc analyses were employed for data extraction $[35,37]$, as they contained additional and relevant information for the assessment of the outcomes of 3 among the 10 pertinent papers $[28,45,49]$. The process of study selection is summarized in Figure 1.
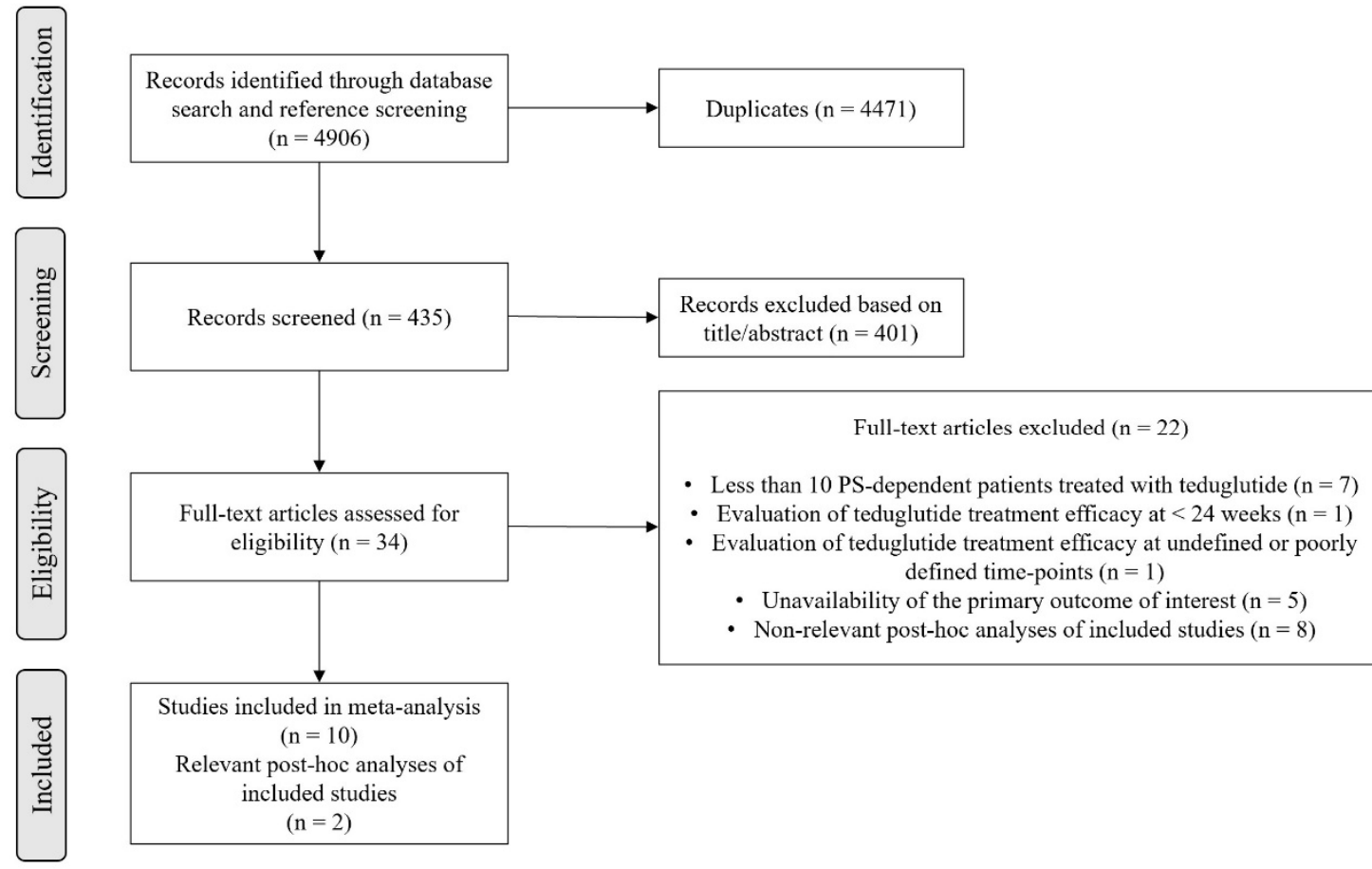

Studies included in meta-analysis $(\mathrm{n}=10)$

Relevant post-hoc analyses of included studies $(n=2)$

Figure 1. Flow-chart of study inclusion. Abbreviations: PS, parenteral support.

\subsection{Characteristics of the Included Studies}

Table 1 summarizes the basic study characteristics. Two studies had a randomized, placebo-controlled, double-blinded design $[27,28]$; the remaining eight studies were characterized by an observational design [43-50]. Among these, one was actually designed as a randomized controlled trial (RCT) [45], but the randomization and the blindness of treatment assignment was performed between different teduglutide dosing schedules rather than between the teduglutide and placebo; therefore, to the scope of our analyses, this study falls in the group of "observational" ones, since both the investigators and the patients were aware that a treatment with the drug was actually in place. 
Table 1. Study characteristics. Abbreviations: N, number; Prosp, prospective; PS, parenteral support; RCT, randomized controlled trial; Retr, retrospective; SBS, short bowel syndrome.

\begin{tabular}{|c|c|c|c|c|c|c|c|c|c|}
\hline First Author, Year & $\begin{array}{l}\text { Study } \\
\text { Design }\end{array}$ & $\begin{array}{c}N \text { of } \\
\text { Patients }\end{array}$ & $\begin{array}{c}\text { Age } \\
\text { (Years) }^{a}\end{array}$ & $\begin{array}{l}\text { Gender } \\
\text { (\% Male) }\end{array}$ & $\begin{array}{l}\text { SBS Etiology } \\
\text { (Crohn/Vascular } \\
\text { /Other) (\%) }\end{array}$ & $\begin{array}{l}\text { Patients with } \\
\text { Colon in } \\
\text { Continuity (\%) }\end{array}$ & $\begin{array}{l}\text { Remnant } \\
\text { Small Bowel } \\
\text { Length } \\
\text { (cm) }\end{array}$ & $\begin{array}{l}\text { Time Since } \\
\text { Start of PS } \\
\text { Dependence } \\
\text { (Years) }^{a}\end{array}$ & $\begin{array}{l}\text { PS Volume } \\
\text { at Baseline } \\
\text { (L/Week) }^{\text {a }}\end{array}$ \\
\hline \multirow{2}{*}{$\begin{array}{l}\text { Jeppesen et al., } \\
2011 \text { [27] }\end{array}$} & \multirow{2}{*}{ RCT } & $67^{b}$ & 48.6 & 44.8 & $34.4 / 32.8 / 32.8$ & 67.2 & 53 & 6.9 & 11.1 \\
\hline & & $16^{\mathrm{c}}$ & 49.4 & 43.8 & $43.7 / 18.8 / 37.5$ & 68.8 & 53 & 7.9 & 10.7 \\
\hline \multirow{2}{*}{$\begin{array}{l}\text { Jeppesen et al., } \\
2012 \text { [28] }\end{array}$} & \multirow{2}{*}{ RCT } & $43^{b}$ & 50.9 & 48.8 & $23.3 / 30.2 / 46.5$ & 60.5 & 138 & 6.8 & 12.9 \\
\hline & & $43^{c}$ & 49.7 & 44.2 & $18.6 / 37.2 / 37.2$ & 53.5 & 123 & 5.9 & 13.2 \\
\hline $\begin{array}{l}\text { Joly et al., } \\
2019 \text { [43] }\end{array}$ & $\begin{array}{l}\text { Retr. } \\
\text { cohort }\end{array}$ & 54 & 52.3 & 64.8 & $29.6 / 38.9 / 31.5$ & 64.8 & 62 & 9.8 & 11.2 \\
\hline $\begin{array}{l}\text { Martin } \\
\text { et al., 2020 [44] }\end{array}$ & $\begin{array}{l}\text { Retr. } \\
\text { cohort }\end{array}$ & 31 & 51.0 & 64.5 & $32.3 / 32.3 / 35.4$ & 51.6 & 74 & 4.8 & 7.5 \\
\hline $\begin{array}{l}\text { O'Keefe et al., } \\
2013 \text { [45] }\end{array}$ & $\begin{array}{l}\text { Prosp. } \\
\text { cohort }\end{array}$ & 52 & 48.1 & 53.8 & $34.6 / 34.6 / 30.8$ & 71.2 & 60 & 7.0 & 11.5 \\
\hline $\begin{array}{l}\text { Pevny et al., } 2018 \\
\text { [46] }\end{array}$ & $\begin{array}{l}\text { Retr. } \\
\text { cohort }\end{array}$ & 27 & 51.0 & 48.1 & $14.8 / 44.4 / 40.8$ & 77.8 & 74 & 4.3 & 13.7 \\
\hline $\begin{array}{l}\text { Puello et al., } 2020 \\
\text { [47] }\end{array}$ & $\begin{array}{c}\text { Retr. } \\
\text { cohort }\end{array}$ & 18 & 54.4 & 44.4 & $55.6 / 16.7 / 27.7$ & 50.0 & 100 & 3.3 & 9.9 \\
\hline $\begin{array}{l}\text { Schoeler et al., } \\
2018 \text { [48] }\end{array}$ & $\begin{array}{l}\text { Prosp. } \\
\text { cohort }\end{array}$ & 14 & 50.5 & 35.7 & $50.0 / 35.7 / 14.3$ & 64.3 & 50 & 5.2 & 12.2 \\
\hline $\begin{array}{l}\text { Schwartz et al., } \\
2016 \text { [49] }\end{array}$ & $\begin{array}{l}\text { Prosp. } \\
\text { cohort }\end{array}$ & 88 & 50.9 & 46.6 & $18.2 / 33.0 / 48.8$ & 61.4 & 50 & 6.4 & 12.2 \\
\hline $\begin{array}{l}\text { Solar et al., } 2020 \\
\text { [50] }\end{array}$ & $\begin{array}{l}\text { Prosp. } \\
\text { cohort }\end{array}$ & 17 & 40.2 & 52.9 & $0.0 / 47.1 / 52.9$ & 94.1 & 38 & 6.5 & 12.1 \\
\hline
\end{tabular}

${ }^{a}$ Data reported as mean or median (according to the information provided by each study), ${ }^{\mathrm{b}}$ Treatment group, c Control group.

The teduglutide dose was $0.05 \mathrm{mg} / \mathrm{kg} /$ day in most studies, with the only exception of two studies, in which the $0.1 \mathrm{mg} / \mathrm{kg} /$ day dose was also used [27,45]. As for the considered time points at which the efficacy of the teduglutide treatment was assessed, both the available RCTs evaluated their end-points after 6 months of treatment [27,28]; an additional four observational studies provided efficacy data at this time-point $[43,46,48,50]$. Five studies, all observational, evaluated teduglutide efficacy after 1 year of treatment [44-48]; three studies provided data about teduglutide efficacy after $\geq 2$ years of treatment $[46,47,49]$ (Table 2).

\subsection{Efficacy of Teduglutide in Achieving PS Reduction}

Considering the two available placebo-controlled trials [27,28], the response rate was significantly greater in the teduglutide than in the placebo group $(+36 \%, 95 \% \mathrm{CI}:(+22 \%$, $+50 \%)$ ) (Figure S1). When pooling the efficacy results of the treatment arms of these trials $[27,28]$ with those of the observational studies that evaluated the primary outcome of interest at 6 months $[43,46,48,50]$, the pooled estimate of the response rate was $64 \%$ (95\%CI: $(45 \%, 81 \%))$ (Figure 2), without a significant difference between RCTs and observational studies $(p=0.50)$ (Figure S2). At 1 year [44-48], the pooled estimate of the response rate was $77 \%$ (95\%CI: $(67 \%, 86 \%)$ ) (Figure 2). At $\geq 2$ years [46,47,49], the pooled estimate of the response rate was $82 \%$ (95\% CI: (65-94\%)) (Figure 2). All these analyses were repeated after excluding the patients treated with a dosing schedule of $0.1 \mathrm{mg} / \mathrm{kg} /$ day, with the overall results being substantially confirmed (Figures S3-S5). 
Table 2. Availability of efficacy data in terms of response rate, at different time points, for each included study; for each time point, the number of patients available for evaluation is reported in brackets.

\begin{tabular}{|c|c|c|c|}
\hline \multirow[t]{2}{*}{ First Author, Year } & \multicolumn{3}{|c|}{$\begin{array}{c}\text { Available Time Points for the Evaluation of Teduglutide Efficacy in Terms of } \\
\text { Response Rate }\end{array}$} \\
\hline & 6 Months & 1 Year & $\geq 2$ Years \\
\hline Jeppesen et al., 2011 [27] & Yes $^{a}(56 \text { pt. })^{b}$ & --- & -- \\
\hline Jeppesen et al., 2012 [28] & Yes $^{a}(39 \text { pt. })^{b}$ & $-\cdots$ & -- \\
\hline Joly et al., 2019 [43] & Yes $^{\text {a }}$ (54 pt.) & --- & -- \\
\hline Martin et al., 2020 [44] & -- & Yes (31 pt.) & -- \\
\hline O'Keefe et al., 2013 [45] & --- & Yes (43 pt.) & -- \\
\hline Pevny et al., 2018 [46] & Yes $^{\text {a }}$ (17 pt.) & Yes (11 pt.) & Yes (7 pt.) \\
\hline Puello et al., 2020 [47] & $-\ldots c$ & Yes (16 pt.) & Yes $^{\mathrm{d}}$ (13 pt.) \\
\hline Schoeler et al., 2018 [48] & Yes $^{\text {a }}$ (12 pt.) & Yes $^{\text {e }}$ (11 pt.) & - \\
\hline Schwartz et al., 2016 [49] & -- & -- & Yes (65 pt.) ${ }^{\mathrm{f}}$ \\
\hline Solar et al., 2020 [50] & Yes $^{\text {a }}$ (17 pt.) & --- & --- \\
\hline
\end{tabular}

a 24 weeks, ${ }^{b}$ Number of patients in the treatment group, ${ }^{\mathrm{c}}$ Data of response rate at 6 months were reported in the original article, but have been excluded from our analysis due to inconsistency between the proportion of responders reported in terms of absolute numbers (16/18 patients) and the same data reported as a percentage $(75 \%)$; this time point, however, was still included in the analysis concerning the weaning rate, as reported data were consistent in terms of this outcome measure, ${ }^{\mathrm{d}}$ Data at 2 years, 3 years, and 5 years were provided in order to include the largest possible number of patients, data at 2 years were considered for quantitative analyses, ${ }^{\mathrm{e}} 48$ weeks, ${ }^{\mathrm{f}} 35$ patients at 24 months, 30 patients at 30 months. Abbreviations: pt, patients; - - -, no available data.

Time group $=6$ months

Jeppesen et al, 2011

Jeppesen et al, 2012

Joly et al, 2019

Pevny et al, 2018

Schoeler et al, 2018

Solar et al, 2020

$\begin{array}{rr}24 & 56 \\ 27 & 39 \\ 46 & 54 \\ 10 & 17 \\ 4 & 12 \\ 14 & 17 \\ & 195\end{array}$

Random effects model

$95 \%-\mathrm{Cl}$ Weight

Heterogeneity: $I^{2}=83 \%, \tau^{2}=0.0407, p<0.01$

Time group $=1$ year

Martin et al, 2020

O' Keefe et al, 2013

Pevny et al, 2018

Puello et al, 2020

Schoeler et al, 2018

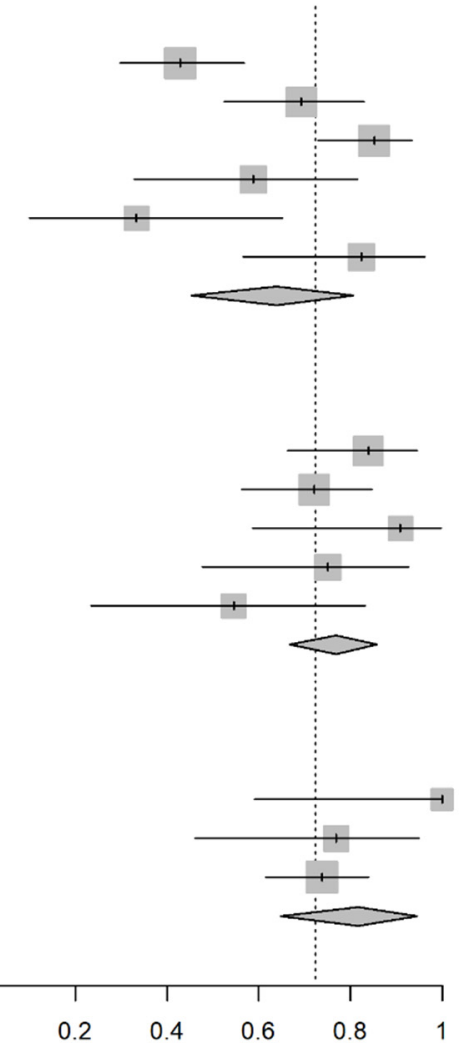

$0.43[0.30 ; 0.57] \quad 9.2 \%$

$0.69[0.52 ; 0.83] \quad 8.5 \%$

$0.85[0.73 ; 0.93] \quad 9.1 \%$

$0.59[0.33 ; 0.82] \quad 6.7 \%$

$0.33[0.10 ; 0.65] \quad 5.8 \%$

$0.82[0.57 ; 0.96] \quad 6.7 \%$

$0.64[0.45 ; 0.81] \quad 45.9 \%$

Random effects mode

$\begin{array}{rr}26 & 31 \\ 31 & 43 \\ 10 & 11 \\ 12 & 16 \\ 6 & 11 \\ & 112\end{array}$

Heterogeneity: $I^{2}=19 \%, \tau^{2}=0.0028, p=0.29$

Time group $=2$ years

Pevny et al, 2018

Puello et al, 2020

Schwartz et al, 2016

$7 \quad 7$

Random effects model

$10 \quad 13$

$48 \quad 65$

Heterogeneity: $I^{2}=43 \%, \tau^{2}=0.0110, p=0.17$

85

0.2

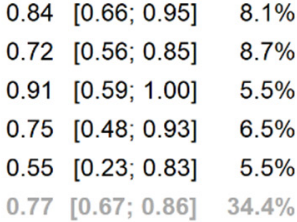

$1.00[0.59 ; 1.00] \quad 4.4 \%$

$0.77 \quad[0.46 ; 0.95] \quad 6.0 \%$

$0.74[0.61 ; 0.84] \quad 9.4 \%$

$0.82[0.65 ; 0.94] \quad 19.7 \%$

Figure 2. Forest plot for the estimation of the response rate at 6 months, 1 year, and $\geq 2$ years. Abbreviations: $\mathrm{CI}$, confidence interval. 
In order to specifically explore possible differences in teduglutide efficacy over time, studies reporting the response rate in the same patient cohort at different time points were selected [27,28,45-49], and differences in the response rate over time were evaluated. A significant increase in response rate could be noted between 6 months and 1 year $(+29 \%$, $95 \%$ CI: $(+14 \%,+43 \%))$, and between 6 months and $\geq 2$ years $(+31 \%, 95 \% \mathrm{CI}:(+14 \%,+47 \%))$; on the contrary, no significant differences emerged between 1 year and $\geq 2$ years $(+7 \%$, $95 \% \mathrm{CI}:(-7 \%,+22 \%))$, even if a trend towards increase could still be noted (Figure 3$)$.

(A)

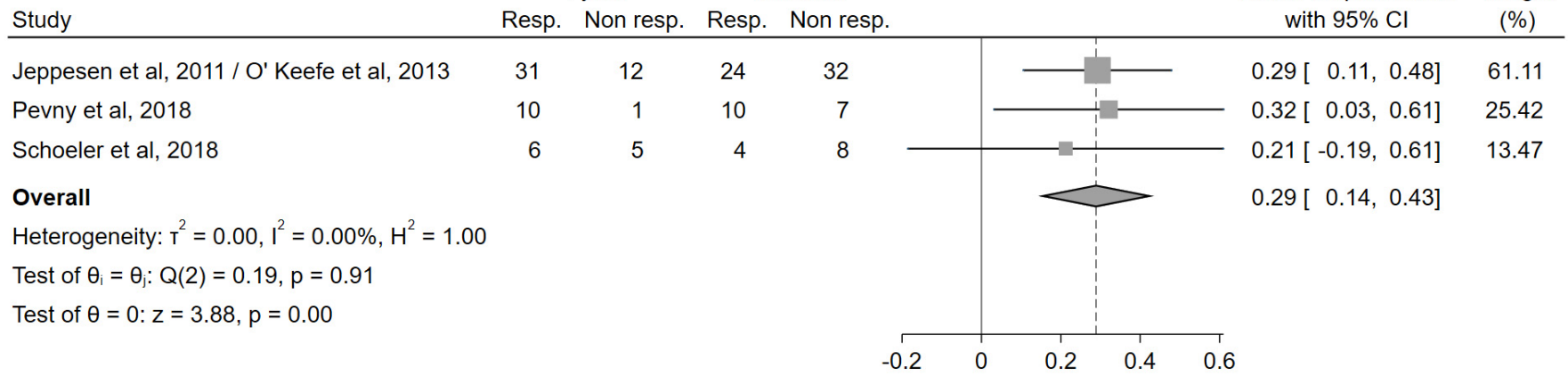

(B)

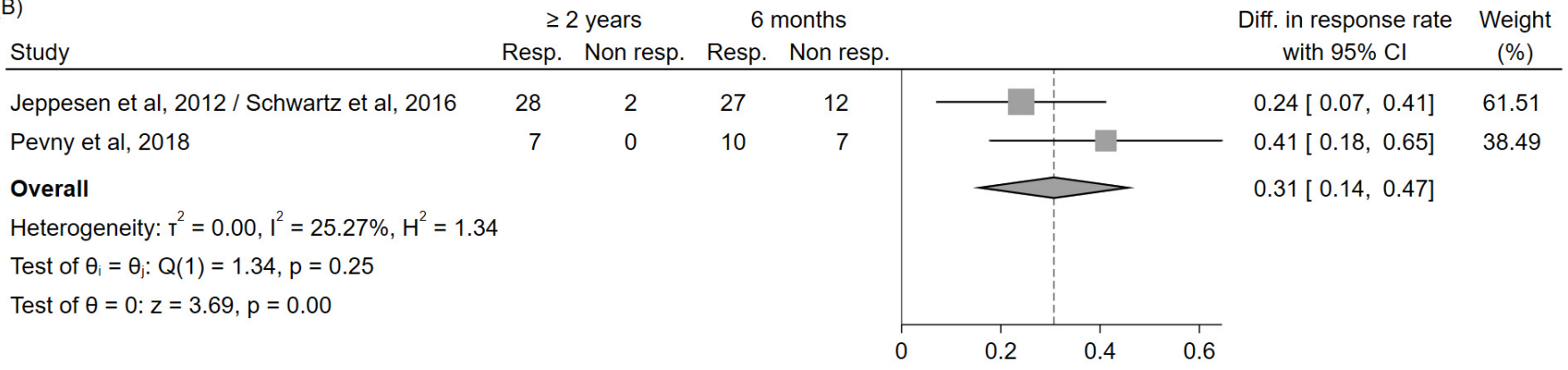

(C) Study $\geq 2$ years 1 year Resp. Non resp. Resp. Non resp.

$\begin{array}{lrrrr}\text { Pevny et al, } 2018 \text { Pevny et al, 2018 Pevny } & 7 & 0 & 10 & 1 \\ \text { Puello et al, 2020 } & 10 & 3 & 12 & 4\end{array}$

Overall

Heterogeneity: $\mathrm{T}^{2}=0.00, \mathrm{I}^{2}=0.00 \%, \mathrm{H}^{2}=1.00$

Test of $\theta_{i}=\theta_{j}: Q(1)=0.16, p=0.69$

Test of $\theta=0: z=0.98, p=0.33$

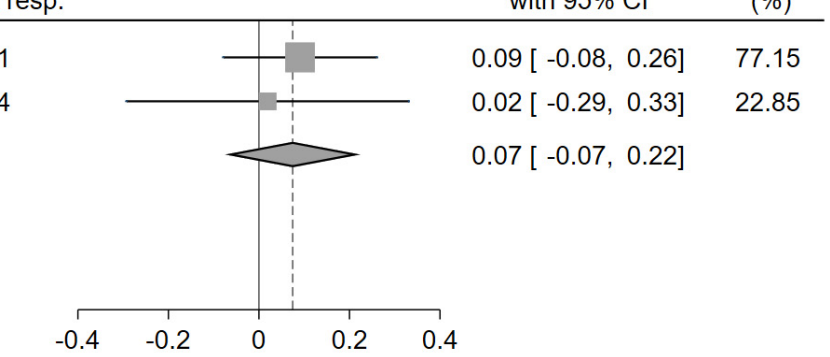

Figure 3. Forest plot for the estimation of the differences in the response rates over time, evaluated in studies reporting these data in the same patient cohort at different time points (1 year vs. 6 months (A); $\geq 2$ years vs. 6 months $(\mathbf{B}) ; \geq 2$ years vs. 1 year $(\mathbf{C})$ ). Abbreviations: CI, confidence interval; Diff., difference; Resp., responders; Non resp., nonresponders; vs., versus.

\subsection{Efficacy of Teduglutide in Achieving PS Independence}

All included studies also evaluated, at the same time points as the primary outcome measure, the proportion of teduglutide-treated patients that could achieve PS independence (weaning rate). The pooled estimates for this outcome were $11 \%(95 \% \mathrm{CI}$ : $(2 \%, 24 \%))$ at 6 months [27,28,43,46-48,50], 17\% (95\%CI: $(9 \%, 26 \%))$ at 1 year [44-48], and $21 \%(95 \% \mathrm{CI}$ : $(12 \%, 31 \%))$ at $\geq 2$ years $[46,47,49]$ (Figure 4$)$. Overall, these results were confirmed even after excluding the patients treated with a dosing schedule of $0.1 \mathrm{mg} / \mathrm{kg} /$ day (Figure S6). 
Study

Weaned Total

Time group $=6$ months Jeppesen et al, 2011

Jeppesen et al, 2012

Joly et al, 2019

Pevny et al, 2018

Puello et al, 2020

Schoeler et al, 2018

Solar et al, 2020

Random effects model

Heterogeneity: $I^{2}=82 \%, \tau^{2}=0.0381, p<0.01$

Time group $=1$ year

Martin et al, 2020

O' Keefe et al, 2013

Pevny et al, 2018

Puello et al, 2020

Schoeler et al, 2018

Random effects model

Heterogeneity: $I^{2}=16 \%, \tau^{2}=0.0023, p=0.31$

Time group $=2$ years

Pevny et al, 2018

Puello et al, 2020

Schwartz et al, 2016

Random effects model

Heterogeneity: $I^{2}=0 \%, \tau^{2}=0, p=0.59$

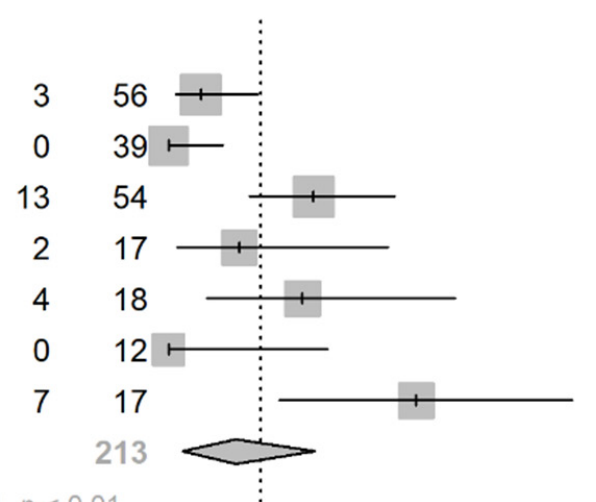

Weaning rate

95\%-Cl Weight

$\begin{array}{lll}0.05 & {[0.01 ; 0.15]} & 8.7 \% \\ 0.00 & {[0.00 ; 0.09]} & 8.0 \% \\ 0.24 & {[0.13 ; 0.38]} & 8.6 \% \\ 0.12 & {[0.01 ; 0.36]} & 6.2 \% \\ 0.22 & {[0.06 ; 0.48]} & 6.4 \% \\ 0.00 & {[0.00 ; 0.26]} & 5.3 \% \\ 0.41 & {[0.18 ; 0.67]} & 6.2 \% \\ 0.11 & {[0.02 ; 0.24]} & 49.4 \%\end{array}$

$0.29[0.14 ; 0.48] \quad 7.6 \%$

$0.09 \quad[0.03 ; 0.22] \quad 8.2 \%$

$0.18 \quad[0.02 ; 0.52] \quad 5.1 \%$

$0.19[0.04 ; 0.46] \quad 6.1 \%$

$0.18 \quad[0.02 ; 0.52] \quad 5.1 \%$

$0.17[0.09 ; 0.26] \quad 32.1 \%$

$\begin{array}{llr}0.29 & {[0.04 ; 0.71]} & 4.0 \% \\ 0.31 & {[0.09 ; 0.61]} & 5.5 \% \\ 0.20 & {[0.11 ; 0.32]} & 8.9 \% \\ 0.21 & {[0.12 ; 0.31]} & 18.4 \%\end{array}$

Figure 4. Forest plot for the estimation of the weaning rate at 6 months, 1 year, and $\geq 2$ years. Abbreviations: $\mathrm{CI}$, confidence interval.

In order to specifically explore possible differences in teduglutide efficacy over time, studies reporting the weaning rate in the same cohort at different time points were selected [27,28,45-49], and differences over time were evaluated. A significant increase in weaning rate could be noted between 6 months and $\geq 2$ years $(+27 \%, 95 \% \mathrm{CI}:(+3 \%,+50 \%))$, mostly driven by the patient cohort analyzed in the studies by Jeppesen et al. [28] and Schwartz et al. [49]; on the contrary, no significant differences emerged between 6 months and 1 year $(+5 \%, 95 \% \mathrm{CI}:(-3 \%,+14 \%))$ or between 1 year and $\geq 2$ years $(+11 \%, 95 \% \mathrm{CI}$ : $(-13 \%,+36 \%))$, even if a trend towards increase could still be noted (Figure 5$)$. 


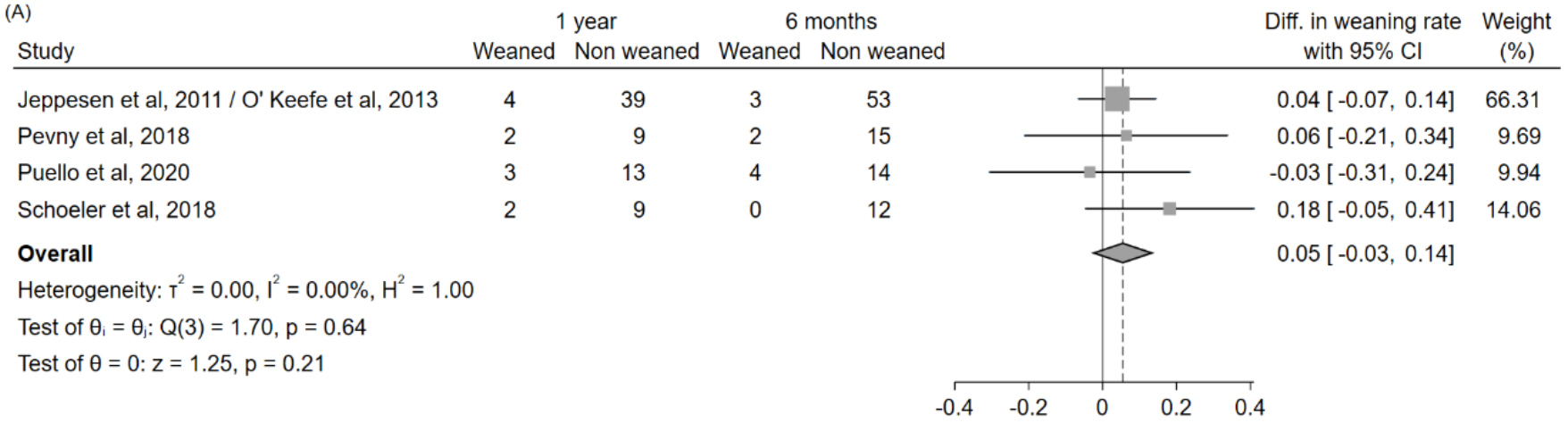

(B)

$\geq 2$ years

1 year

Diff. in weaning rate Weight

Study

Weaned Non weaned Weaned Non weaned

Jeppesen et al, 2012 / Schwartz et al, 2016

Pevny et al, 2018

Puello et al, 2020

$\begin{array}{rl}17 & 0 \\ 5 & 2 \\ 9 & 4\end{array}$

Overall

Heterogeneity: $\mathrm{T}^{2}=0.02, \mathrm{I}^{2}=53.91 \%, \mathrm{H}^{2}=2.17$

Test of $\theta_{\mathrm{i}}=\theta_{\mathrm{j}}: \mathrm{Q}(2)=4.34, \mathrm{p}=0.11$

Test of $\theta=0: z=2.19, p=0.03$

\begin{tabular}{ll|l|lll}
39 & & & $0.43[0.26,0.61]$ & 45.76 \\
15 & & & $0.17[-0.20,0.54]$ & 24.81 \\
14 & & & $0.09[-0.23,0.40]$ & 29.43 \\
& & & $0.27[0.03,0.50]$ &
\end{tabular}

(C)

Study
Pevny et al, 2018 Pevny et al, 2018 Pevny
Puello et al, 2020
Overall
Heterogeneity: $\mathrm{T}^{2}=0.00, \mathrm{I}^{2}=0.00 \%, \mathrm{H}^{2}=1.00$
Test of $\theta_{\mathrm{i}}=\theta_{\mathrm{j}}: \mathrm{Q}(1)=0.00, p=0.95$
Test of $\theta=0: z=0.90, p=0.37$

$\geq 2$ years 1 year

Weaned Non weaned Weaned Non weaned

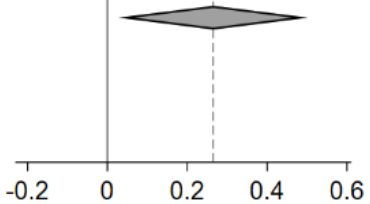

$\begin{array}{llll}2 & 5 & 2 & 9\end{array}$

49

13

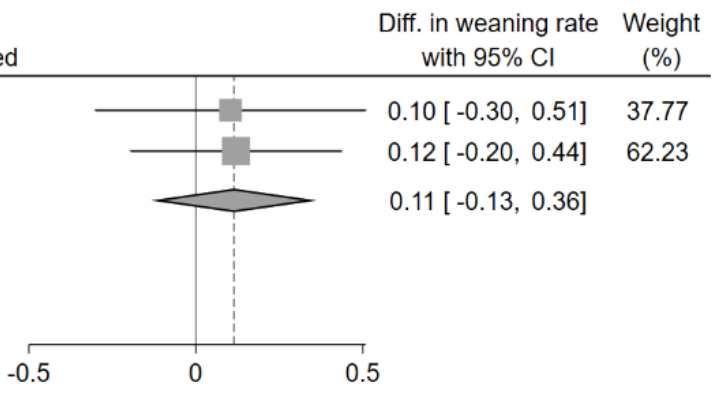

Figure 5. Forest plot for the estimation of the differences in the weaning rate over time, evaluated in studies reporting these data in the same patient cohort at different time points (1 year vs. 6 months (A); $\geq 2$ years vs. 6 months (B); $\geq 2$ years vs. 1 year (C)). Abbreviations: CI, confidence interval; Diff., difference; vs., versus.

\subsection{Relationship between Teduglutide Efficacy and Intestinal Anatomy}

Three studies $[28,43,44]$ reported sufficient data to compare the response rate among patients with or without colon in continuity; two of them evaluated this outcome at 6 months [28,43], and one at 1 year [44]; the latter [44], however, had to be excluded from the analysis due to partial patient overlap with one of the previous two [43]. The response rate was significantly lower $(-17 \%, 95 \% \mathrm{CI}:(-31 \%,-3 \%))$ among patients with colon in continuity (Figure 6A). Six studies $[43,45-47,49,50]$ reported sufficient data to compare the weaning rate among those with or without colon in continuity; one of them evaluated this outcome at 6 months [43], one at 1 year [45], one at $\geq 2$ years [49], and three at the last available follow-up $[46,47,50]$. The weaning rate was significantly higher $(+16 \%, 95 \% \mathrm{CI}$ : $(+6 \%,+25 \%))$ among those with colon in continuity (Figure 6B). No further analyses could be conducted to differentiate the outcomes according to a finer classification of intestinal anatomy due to the paucity of available data; in particular, no sufficient data were available to compare these outcomes between patients with different types of stomas. 
(A) Study Colon-in-continuity Other anatomy

\begin{tabular}{lcccc} 
& Resp. & Non resp. & Resp. & Non resp. \\
\hline Jeppesen et al, 2012 & 14 & 12 & 13 & 4 \\
Joly et al, 2019 & 28 & 7 & 18 & 1
\end{tabular}

\section{Overall}

Heterogeneity: $\mathrm{T}^{2}=0.00, \mathrm{I}^{2}=0.00 \%, \mathrm{H}^{2}=1.00$

Test of $\theta_{i}=\theta_{j}: Q(1)=0.23, p=0.63$

Test of $\theta=0: z=-2.31, p=0.02$

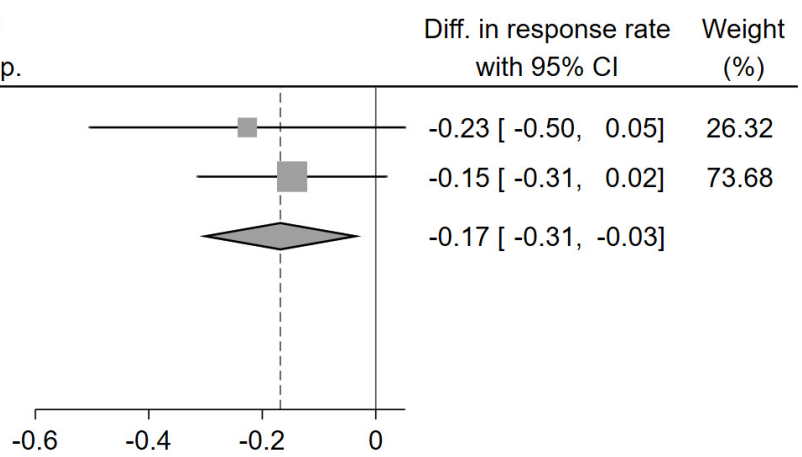

(B)

\begin{tabular}{|c|c|c|c|c|}
\hline B) & Colon-i & -continuity & Othe & anato \\
\hline Study & Weaned & Non weaned & Weaned & Non \\
\hline Joly et al, 2019 & 11 & 24 & 2 & \\
\hline O' Keefe et al, 2013 & 3 & 16 & 0 & \\
\hline Pevny et al, 2018 & 2 & 19 & 0 & \\
\hline Puello et al, 2020 & 3 & 6 & 2 & \\
\hline Schwartz et al, 2016 & 9 & 45 & 4 & \\
\hline Solar et al, 2020 & 7 & 9 & 0 & \\
\hline Overall & & & & \\
\hline Heterogeneity: $\tau^{2}=0$ & $1, I^{2}=39$ & $8 \%, H^{2}=1.64$ & & \\
\hline Test of $\theta_{i}=\theta_{j}: Q(5)=$ & $21, p=0$ & & & \\
\hline Test of $\theta=0: z=3.12$ & $p=0.00$ & & & \\
\hline
\end{tabular}

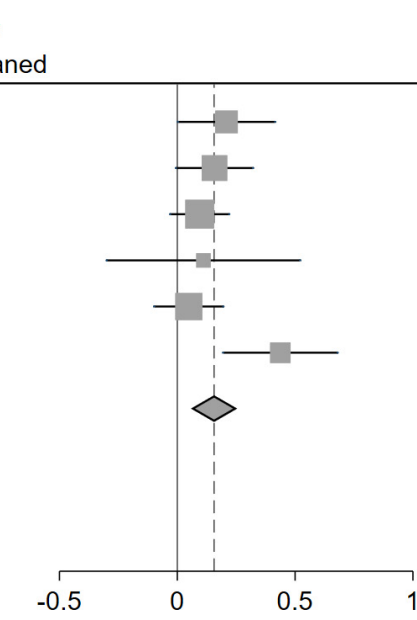

Diff. in weaning rate Weight with $95 \% \mathrm{Cl} \quad(\%)$

0.21 [ $0.00,0.42] 14.98$

0.16 [ $-0.01,0.32] \quad 19.88$

$0.10[-0.03,0.22] \quad 25.83$

$0.11[-0.30,0.52] \quad 5.06$

$0.05[-0.10,0.20] \quad 22.32$

$0.44[0.19,0.68] \quad 11.93$

$0.16[0.06,0.25]$

Figure 6. Forest plot comparing the response rate (A) and the weaning rate $(\mathbf{B})$ according to the presence or the absence of colon in continuity. Reported results did not account for dropouts due to insufficient data. In the study by $\mathrm{O}^{\prime}$ Keefe et al., only the data concerning patients treated with the $0.05 \mathrm{mg} / \mathrm{kg} /$ day dosing schedule could be extracted. Abbreviations: CI, confidence interval; Diff., difference; Resp., responders; Non resp., non responders.

\subsection{Relationship between Teduglutide Efficacy and SBS Etiology}

Three studies $[28,43,44]$ reported sufficient data to compare the response rate among patients with SBS due to Crohn's disease or with SBS due to a different etiology; two of them evaluated this outcome at 6 months [28,43], and one at 1 year [44]; the latter [44], however, had to be excluded from the analysis due to partial patient overlap with one of the previous two [43]. The response rate did not significantly differ between the two groups, although a nonsignificant trend toward a slightly better outcome among patients with SBS due to Crohn's disease could be observed (+9\%, 95\%CI: $(-8 \%,+27 \%))$ (Figure 7A). Five studies $[43,45-47,49]$ reported sufficient data to compare the weaning rate among patients with SBS due to Crohn's disease or with SBS due to a different etiology; one of them evaluated this outcome at 6 months [43], one at 1 year [45], one at $\geq 2$ years [49], and two at the last available follow-up $[46,47]$. The weaning rate did not significantly differ between the two groups, although a nonsignificant trend toward a slightly better outcome among patients with SBS due to Crohn's disease could be observed $(+7 \%, 95 \% \mathrm{CI}:(-14 \%$, $+28 \%$ ) ) (Figure 7B). No further analyses could be conducted to differentiate the outcomes according to a finer classification of SBS etiology due to the paucity of available data. 
(A)

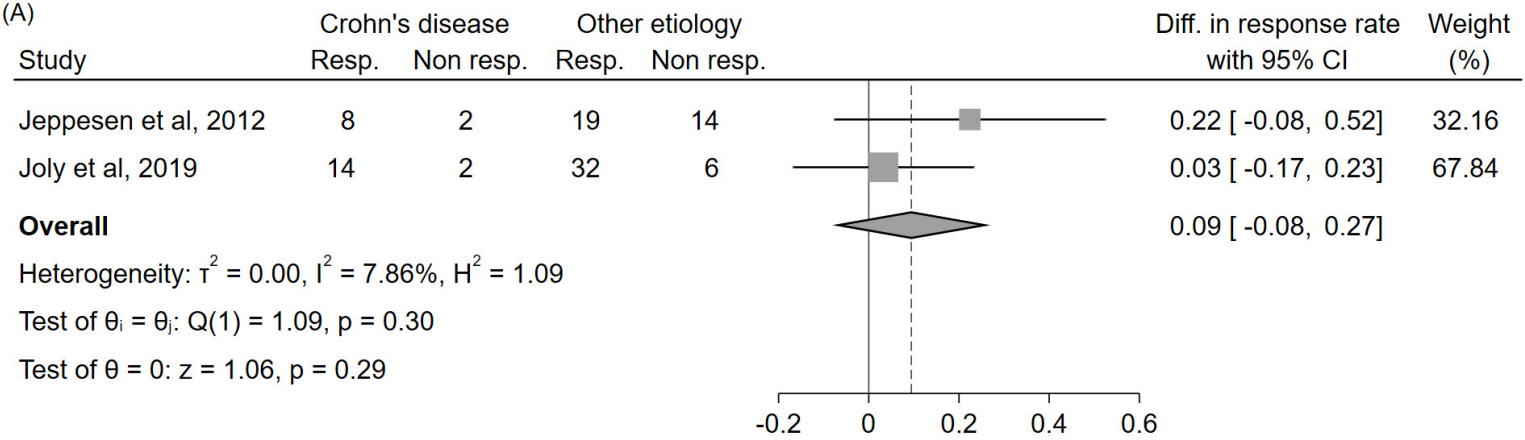

(B)

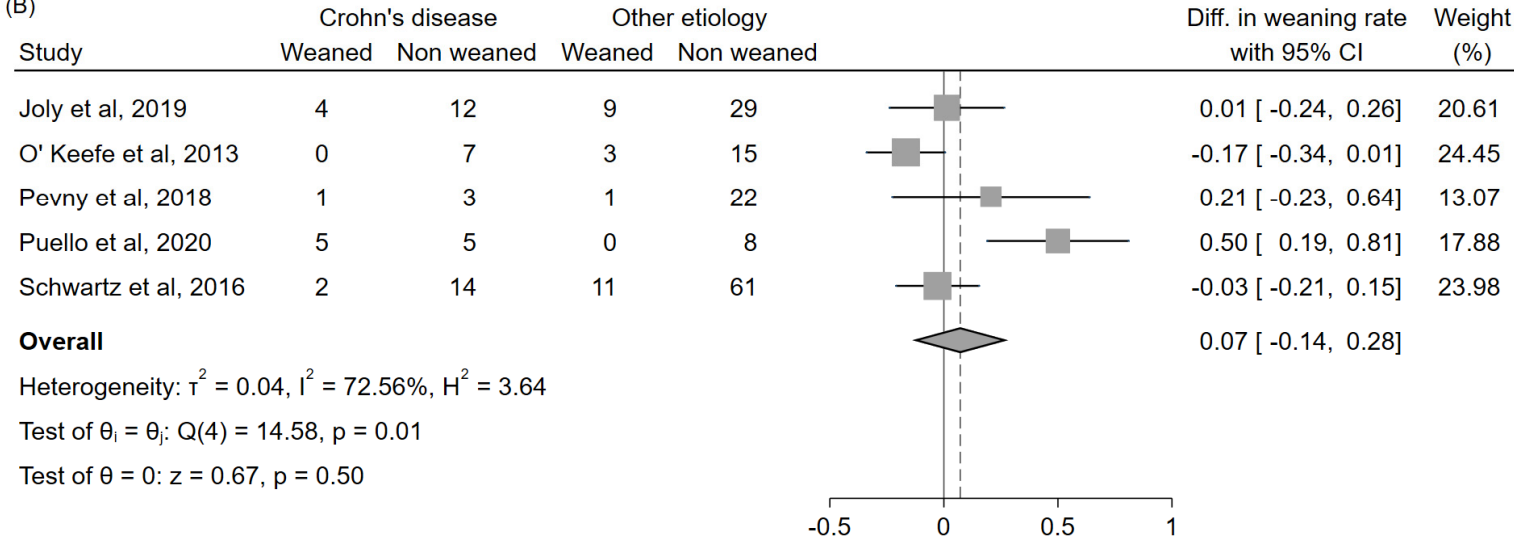

Figure 7. Forest plot comparing the response rate (A) and the weaning rate (B) according to SBS etiology. Reported results do not account for dropouts due to insufficient data. In the study by O'Keefe et al., only the data concerning patients treated with the $0.05 \mathrm{mg} / \mathrm{kg} /$ day dosing schedule could be extracted. Abbreviations: CI, confidence interval; Diff., difference; Resp., responders; Non resp., nonresponders.

\subsection{Quality Assessment and Publication Bias}

The results of the quality assessment of the studies are reported in Tables S1 and S2. Altogether, the risk of bias was moderate-to-low in all studies, with the most relevant concerns being related to possible confounding and selection bias in some of the included observational studies. No significant publication bias was found with Begg's test with respect to the primary outcome measure at any of the considered time points $(p=0.70$ for the studies at 6 months, $p=0.80$ for the studies at 1 year, $p=0.12$ for the studies at $\geq 2$ years).

\section{Discussion}

\subsection{Overall Efficacy}

The results of this systematic review and meta-analysis confirm the efficacy of teduglutide for parenteral support reduction in adult patients with SBS. As a primary outcome measure, we evaluated the proportion of patients achieving a $\geq 20 \%$ reduction in PS volume during teduglutide treatment ("response rate"); this choice was consistent with the available literature, in which this cut-off had been unanimously considered as the one of choice for the distinction between responders and non-responders. As a secondary outcome measure, we evaluated the proportion of patients achieving PS independence ("weaning rate").

The results of our analyses show that the response rate to teduglutide treatment could be estimated as $64 \%$ at 6 months, $77 \%$ at 1 year, and $82 \%$ at $\geq 2$ years; on the other hand, the weaning rate could be estimated as $11 \%$ at 6 months, $17 \%$ at 1 year, and $21 \%$ at $\geq 2$ years. When specifically addressing the question of the course of the response to teduglutide over 
time, the response rate showed a significant increase between 6 months and 1 year and was at least maintained afterwards. Data about the weaning rate were less clear, even if a trend towards an increase in efficacy over time could still be noted. This result is in line with the notion that, as already supposed by other authors $[35,45,49]$, the benefit of teduglutide treatment for PS volume reduction might not only be sustained, but likely increases over time after treatment initiation.

\subsection{Efficacy by Intestinal Anatomy}

Our analysis shows that the efficacy of teduglutide was significantly influenced by intestinal anatomy; the presence of colon in continuity reduced the response rate by $-14 \%$, but, conversely, was associated with an increase in weaning rate of $+16 \%$.

With respect to the response rate, our findings reinforce those already obtained by previous studies [33-35], in which lower PS volume reductions could be observed in patients with colon in continuity compared to those with jejunostomy/ileostomy. Phenotypically, patients with jejunostomy/ileostomy are frequently characterized by accelerated gastric emptying, poor adaptation following resection, and higher PS volume needs [33,51,52]. In these patients, a reduced endogenous GLP-2 secretion was reported, as a consequence of the resection of the terminal ileum and the colon, where the L-cells are predominantly located $[33,53,54]$; on the contrary, in patients with colon in continuity, the endogenous GLP-2 secretion is essentially preserved $[33,53,54]$. Therefore, patients experiencing the most pronounced benefits from the administration of an exogenous GLP-2 analog would most probably be those without colon in continuity.

Regarding the weaning rate, irrespectively to teduglutide treatment, the presence of colon in continuity is known to be associated with lower PS volume needs and a higher probability of progressive spontaneous adaptation with possible weaning from PS after an intestinal resection [2,55-57]. In general, patients with colon in continuity may have a greater innate potential for adaptation because of the colon's role in fluid absorption and energy conservation [2,33]. Thus, a similar result could also be expected among teduglutidetreated patients. However, even though some authors have already pointed out a possible tendency towards a higher weaning rate among teduglutide-treated patients with colon in continuity compared to those with other intestinal anatomies $[37,43,49]$, none of the published studies were able to reach a statistical significance on this outcome in univariate analysis, probably due to the low number of included patients. Therefore, our study was the first to actually prove a statistically significant difference in weaning rates between patients with and without colon in continuity.

In summary, the available evidence suggests that the presence/absence of colon in continuity predicts in a different and opposite way the achievement of response and/or weaning after the initiation of teduglutide treatment. This may be explained by the fact that these two processes likely recognize different pathophysiological mechanisms and, thus, different predictors. The achievement of a $\geq 20 \%$ reduction in PS (commonly adopted as the definition of "response") is more likely to be associated with higher baseline PS volume needs and the absence of a residual endogenous GLP-2 secretion; on the contrary, the possibility of completely weaning off PS is more likely associated with lower baseline PS volume needs and the preservation of a certain amount of resorptive capacity by residual colon.

\subsection{Efficacy by SBS Etiology}

Our analysis did not show any significant difference in teduglutide efficacy according to SBS etiology. Nevertheless, a nonsignificant trend toward a slightly better outcome among patients with SBS due to Crohn's disease could be observed, both in terms of response rate and weaning rate.

With respect to the response rate, a possible explanation for this finding might be related to the fact that PS-dependent patients due to Crohn's disease are more likely to 
have no colon in continuity and higher PS volume needs [33,37,43], with the implications already described within the previous paragraph.

Regarding the weaning rate, the slight tendency towards an increased weaning probability among patients with Crohn's disease held true even though the majority these patients did not have colon in continuity $[33,37,43]$, which we showed to be a condition associated per se with lower weaning rates. Therefore, it might be argued that an SBS etiology due to Crohn's disease might actually be a positive predictive factor for weaning, but that this could not be highlighted in our analysis due to the unavailability of individual patient data, and to the consequent impossibility of controlling the role of intestinal anatomy as a confounder and/or effect modifier. This reasoning, though speculative, would overall be in line with some preliminary findings by Joly et al. [43], which found that Crohn's disease was not a predictor of weaning at univariate analysis $(p=0.91)$ but almost reached a statistical significance at multivariate regression after adjustment for age, intestinal length, and intestinal anatomy $(p=0.06)$.

\subsection{Strengths and Limitations}

This was the first meta-analysis that quantitatively assessed the efficacy of teduglutide in patients with SBS, providing pooled estimates of the response rate and the weaning rate among teduglutide-treated patients over time. It confirms and reinforces the findings of previous studies about the role of intestinal anatomy and SBS etiology as predictors of response. Moreover, it better clarifies their role as predictors of weaning, as no clear evidence was available in this regard.

Our analysis had some limitations. First, the robustness of the conclusions was limited by the low number of available studies and patients; this was particularly true for the subanalyses that examined the role of intestinal anatomy and SBS etiology as predictors of the outcome, whose results were weakened by the paucity of available data. Second, the quality was limited by that of the included studies, which were mostly characterized by an observational design; however, the risk of bias was generally moderate-to-low, which confirmed the likely small impact of this issue on the final results. Third, patients' inclusion criteria and PS adjustment protocols were partly different between studies, and this could be responsible for a certain degree of heterogeneity in the considered outcomes; however, heterogeneity is a common limitation of all meta-analyses, and appropriate statistical methods - such as the use of a random-effect model-were adopted to account for it. Fourth, the comparison of response and weaning rates according to intestinal anatomy and SBS etiology were based on crude rate differences, as derived by univariate analyses; thus, the possible interplay between these predictors could not be evaluated.

\section{Conclusions}

In conclusion, our meta-analysis confirms the efficacy of teduglutide for PS reduction and/or discontinuation in adult patients with SBS, with a benefit increasing over time up to at least 1 year from treatment initiation. The presence of colon in continuity was a negative predictive factor for response but a positive predictive factor for weaning. An SBS etiology due to Crohn's disease might be a positive predictive factor for both response and weaning, but the available data were insufficient to draw definite conclusions. 
Supplementary Materials: The following supporting information can be downloaded at: https: / / www.mdpi.com/article/10.3390/nu14040796/s1. Table S1: risk of bias assessment of the RCTs according to RoB 2 tool; Table S2: risk of bias assessment of the observational studies according to ROBINS-I tool; Figure S1: Forest plot for the evaluation of the difference in response rate between the teduglutide and the placebo group in the available RCTs; Figure S2: subgroup analysis for the comparison of the response rate at 6 months in observational studies and RCTs; Figure S3: forest plot for the evaluation of the difference in response rate between the teduglutide and the placebo group in the available RCTs, after the exclusion of the patients treated with a teduglutide dosing schedule of $0.1 \mathrm{mg} / \mathrm{kg} /$ day; Figure S4: forest plot for the estimation of response rate at 6 months, 1 year, and $\geq 2$ years, after the exclusion of the patients treated with a teduglutide dosing schedule of $0.1 \mathrm{mg} / \mathrm{kg} /$ day; Figure S5: subgroup analysis for the comparison of the response rate at 6 months in observational studies and RCTs, after the exclusion of the patients treated with a teduglutide dosing schedule of $0.1 \mathrm{mg} / \mathrm{kg} /$ day; Figure S6: Forest plot for the estimation of the weaning rate at 6 months, 1 year, and $\geq 2$ years, after the exclusion of the patients treated with a teduglutide dosing schedule of $0.1 \mathrm{mg} / \mathrm{kg} /$ day.

Author Contributions: Conceptualization, F.B., C.D., F.D.M., U.A. and S.B.; methodology, F.B., S.B.; validation, F.B., C.D., F.D.M., U.A. and S.B.; formal analysis, F.B.; investigation, F.B., C.D. and S.B.; data curation, F.B., C.D., M.P., V.P. and S.B.; writing, F.B., C.D. and S.B.; visualization, F.D.M., U.A., M.O., A.C., A.D.F., E.G. and S.B.; supervision, F.D.M., U.A., M.O., A.C., A.D.F., E.G. and S.B. All authors have read and agreed to the published version of the manuscript.

Funding: This research received no external funding.

Institutional Review Board Statement: Not applicable.

Informed Consent Statement: Not applicable.

Data Availability Statement: Not applicable.

Conflicts of Interest: F.D.M., U.A. and M.O. received support for attending meetings from Takeda. The other authors report no conflicts of interest in this work.

\section{Appendix A}

Electronic search strategy.

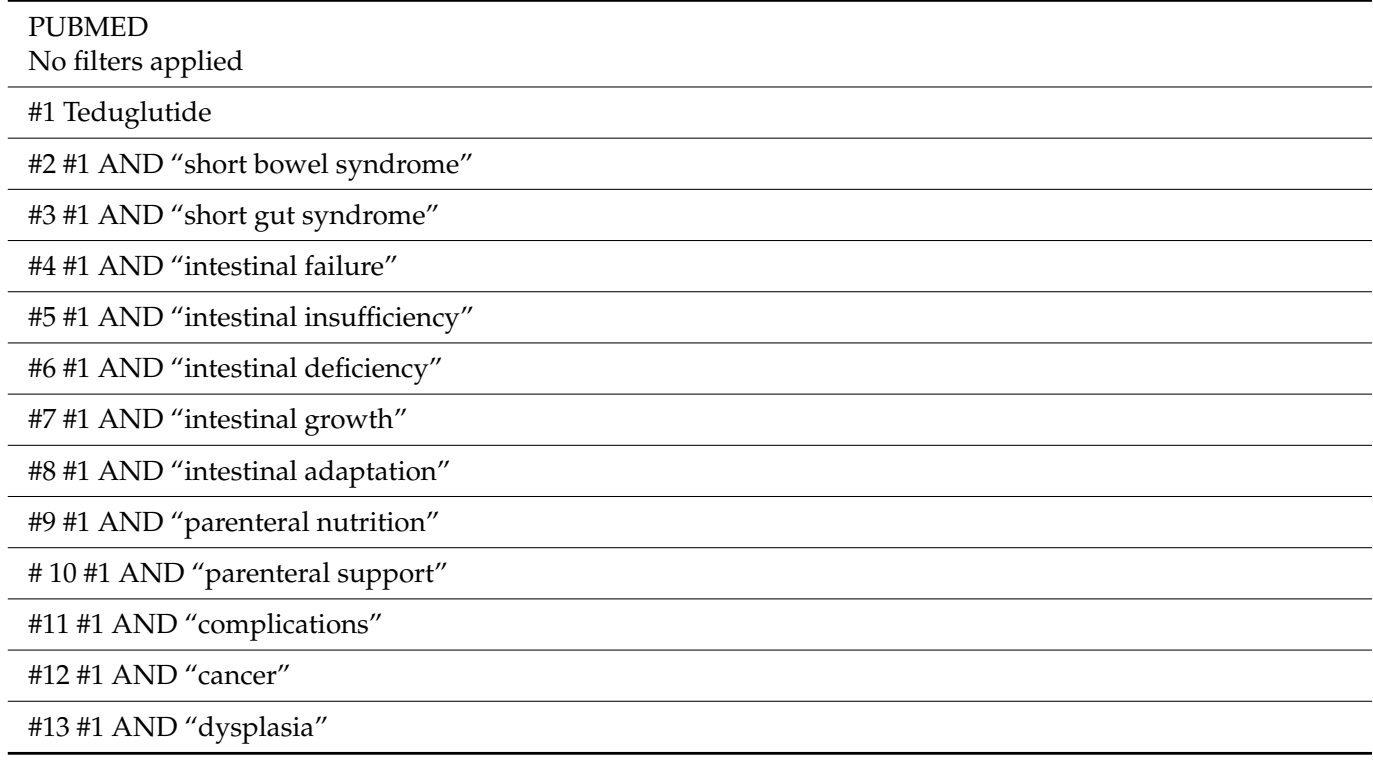




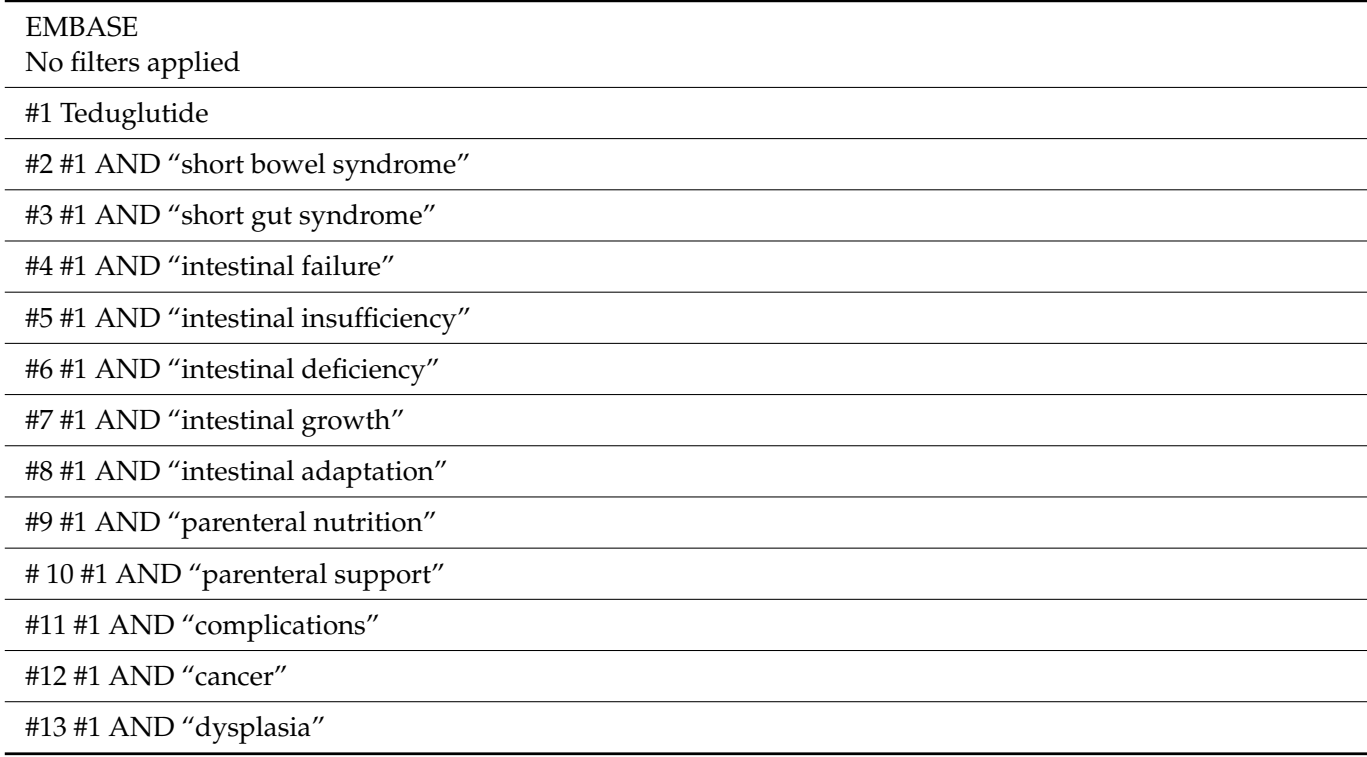

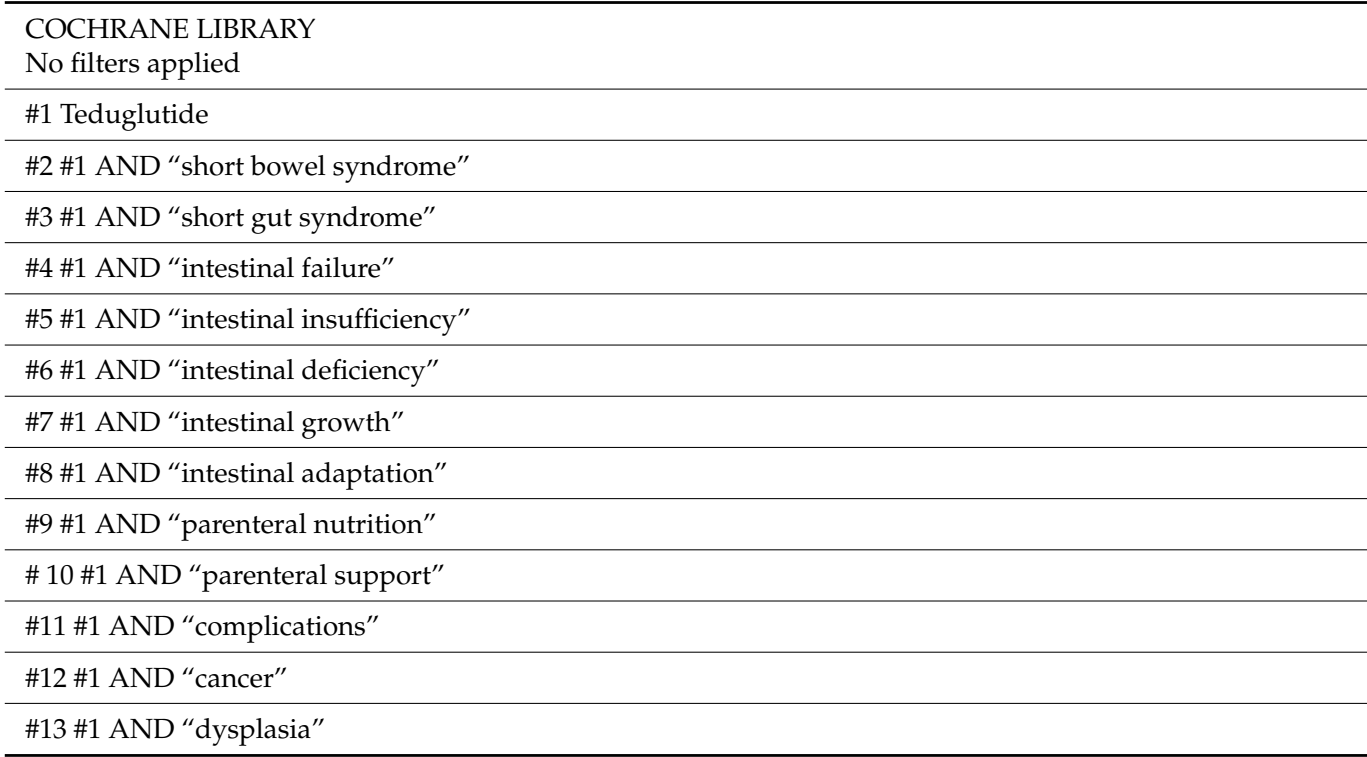

\section{OVID}

No filters applied

\#1 Teduglutide

\#2 \#1 AND "short bowel syndrome"

\#3 \#1 AND "short gut syndrome"

\#4 \#1 AND "intestinal failure"

\#5 \#1 AND "intestinal insufficiency"

\#6 \#1 AND "intestinal deficiency"

\#7 \#1 AND "intestinal growth"

\#8 \#1 AND "intestinal adaptation"

\#9 \#1 AND "parenteral nutrition"

\# 10 \#1 AND "parenteral support"

\#11 \#1 AND "complications"

\#12 \#1 AND "cancer"

\#13 \#1 AND "dysplasia" 


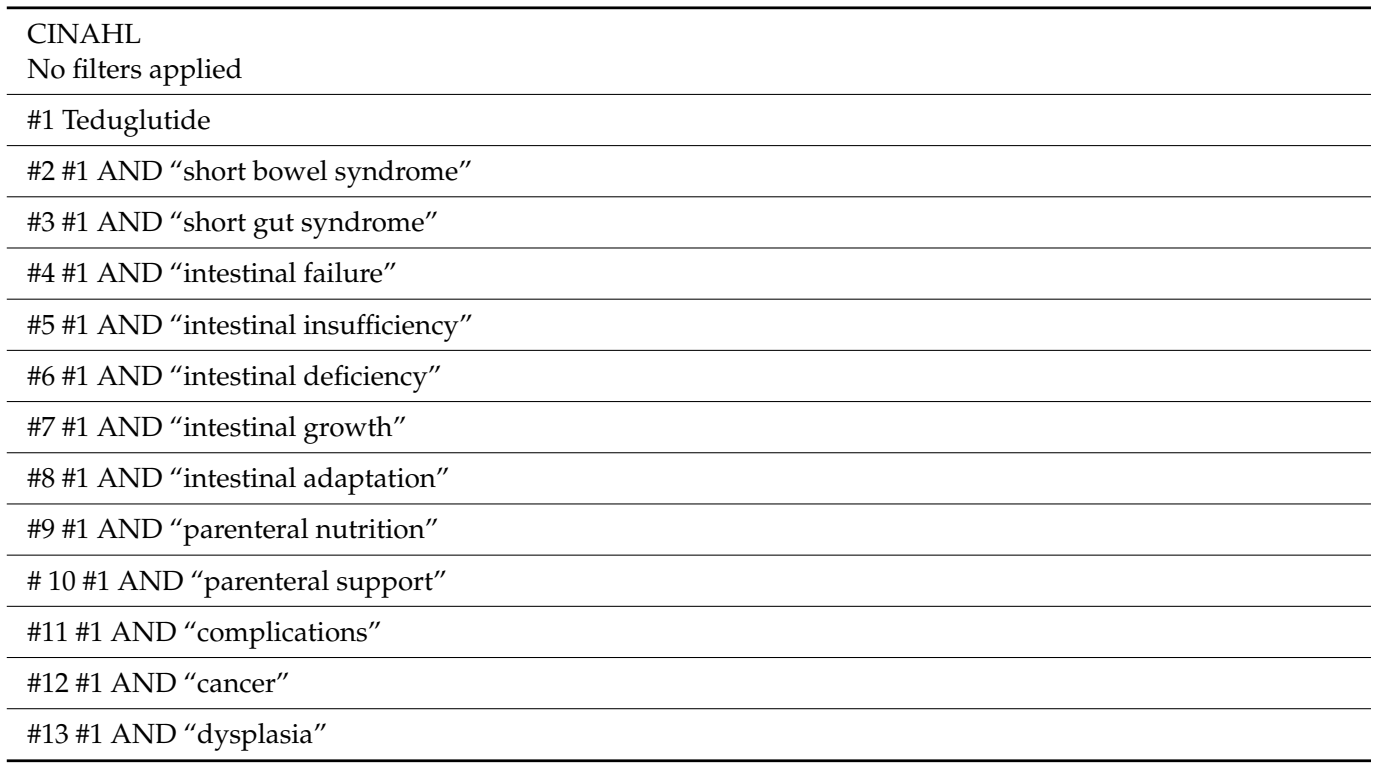

\section{References}

1. Cuerda, C.; Pironi, L.; Arends, J.; Bozzetti, F.; Gillanders, L.; Jeppesen, P.B.; Joly, F.; Kelly, D.; Lal, S.; Staun, M.; et al. ESPEN practical guideline: Clinical nutrition in chronic intestinal failure. Clin. Nutr. 2021, 40, 5196-5220. [CrossRef] [PubMed]

2. Pironi, L.; Arends, J.; Bozzetti, F.; Cuerda, C.; Gillanders, L.; Bekker Jeppesen, P.; Joly, F.; Kelly, D.; Lal, S.; Staun, M.; et al. ESPEN guidelines on chronic intestinal failure in adults. Clin. Nutr. 2016, 35, 247-307. [CrossRef] [PubMed]

3. Pironi, L.; Corcos, O.; Forbes, A.; Holst, M.; Joly, F.; Jonkers, C.; Klek, S.; Lal, S.; Blaser, A.R.; Rollins, K.E.; et al. Intestinal failure in adults: Recommendations from the ESPEN expert groups. Clin. Nutr. 2018, 37, 1798-1809. [CrossRef]

4. Pironi, L.; Arends, J.; Baxter, J.; Bozzetti, F.; Peláez, R.B.; Cuerda, C.; Forbes, A.; Gabe, S.; Gillanders, L.; Holst, M.; et al. ESPEN endorsed recommendations. Definition and classification of intestinal failure in adults. Clin. Nutr. 2015, 34, 171-180. [CrossRef]

5. Pironi, L.; Konrad, D.; Brandt, C.; Joly, F.; Wanten, G.; Agostini, F.; Chambrier, C.; Aimasso, U.; Zeraschi, S.; Kelly, D.; et al. Clinical classification of adult patients with chronic intestinal failure due to benign disease: An international multicenter cross-sectional survey. Clin. Nutr. 2018, 37, 728-738. [CrossRef] [PubMed]

6. Staun, M.; Pironi, L.; Bozzetti, F.; Baxter, J.; Forbes, A.; Joly, F.; Jeppesen, P.; Moreno, J.; Hébuterne, X.; Pertkiewicz, M.; et al. ESPEN Guidelines on Parenteral Nutrition: Home parenteral nutrition (HPN) in adult patients. Clin. Nutr. 2009, 28, 467-479. [CrossRef] [PubMed]

7. Pironi, L.; Boeykens, K.; Bozzetti, F.; Joly, F.; Klek, S.; Lal, S.; Lichota, M.; Mühlebach, S.; Van Gossum, A.; Wanten, G.; et al. ESPEN guideline on home parenteral nutrition. Clin. Nutr. 2020, 39, 1645-1666. [CrossRef] [PubMed]

8. Pironi, L.; Steiger, E.; Brandt, C.; Joly, F.; Wanten, G.; Chambrier, C.; Aimasso, U.; Sasdelli, A.S.; Zeraschi, S.; Kelly, D.; et al. Home parenteral nutrition provision modalities for chronic intestinal failure in adult patients: An international survey. Clin. Nutr. 2020, 39, 585-591. [CrossRef] [PubMed]

9. Reber, E.; Staub, K.; Schönenberger, K.; Stanga, A.; Leuenberger, M.; Pichard, C.; Schuetz, P.; Mühlebach, S.; Stanga, Z. Management of Home Parenteral Nutrition: Complications and Survival. Ann. Nutr. Metab. 2021, 77, 46-55. [CrossRef]

10. Lee, W.; Chew, K.; Ng, R.; Kasmi, K.; Sokol, R. Intestinal failure-associated liver disease (IFALD): Insights into pathogenesis and advances in management. Hepatol. Int. 2020, 14, 305-316. [CrossRef]

11. Napartivaumnuay, N.; Gramlich, L. The Prevalence of Vitamin D Insufficiency and Deficiency and Their Relationship with Bone Mineral Density and Fracture Risk in Adults Receiving Long-Term Home Parenteral Nutrition. Nutrients 2017, 9, 481. [CrossRef]

12. Saqui, O.; Fernandes, G.; Allard, J. Central venous catheter infection in Canadian home parenteral nutrition patients: A 5-year multicenter retrospective study. Br. J. Nurs. 2020, 29, S34-S42. [CrossRef]

13. Brandt, C.; Tribler, S.; Hvistendahl, M.; Naimi, R.; Brøbech, P.; Staun, M.; Jeppesen, P. Home Parenteral Nutrition in Adult Patients with Chronic Intestinal Failure: Catheter-Related Complications over 4 Decades at the Main Danish Tertiary Referral Center. JPEN J. Parenter. Enteral Nutr. 2018, 42, 95-103. [CrossRef]

14. Sowerbutts, A.; Jones, D.; Lal, S.; Burden, S. Quality of life in patients and in family members of those receiving home parenteral support with intestinal failure: A systematic review. Clin. Nutr. 2021, 40, 3210-3220. [CrossRef] [PubMed]

15. Baxter, J.P.; Fayers, P.M.; Bozzetti, F.; Kelly, D.; Joly, F.; Wanten, G.; Jonkers, C.; Cuerda, C.; van Gossum, A.; Klek, S.; et al. An international study of the quality of life of adult patients treated with home parenteral nutrition. Clin. Nutr. 2019, 38, 1788-1796. [CrossRef] [PubMed]

16. Arhip, L.; Camblor, M.; Bretón, I.; Motilla, M.; Serrano-Moreno, C.; Frías, L.; Velasco, C.; Carrascal, M.; Morales, A.; Cuerda, C. Social and economic costs of home parenteral nutrition. Clin. Nutr. ESPEN 2020, 40, 103-109. [CrossRef] [PubMed] 
17. Arhip, L.; Serrano-Moreno, C.; Romero, I.; Camblor, M.; Cuerda, C. The economic costs of home parenteral nutrition: Systematic review of partial and full economic evaluations. Clin. Nutr. 2021, 40, 339-349. [CrossRef] [PubMed]

18. Seidner, D.; Fujioka, K.; Boullata, J.; Iyer, K.; Lee, H.; Ziegler, T. Reduction of Parenteral Nutrition and Hydration Support and Safety with Long-Term Teduglutide Treatment in Patients with Short Bowel Syndrome-Associated Intestinal Failure: STEPS-3 Study. Nutr. Clin. Pract. 2018, 33, 520-527. [CrossRef] [PubMed]

19. Jeppesen, P. Teduglutide, a novel glucagon-like peptide 2 analog, in the treatment of patients with short bowel syndrome. Therap. Adv. Gastroenterol. 2012, 5, 159-171. [CrossRef] [PubMed]

20. Jeppesen, P. Gut hormones in the treatment of short-bowel syndrome and intestinal failure. Curr. Opin. Endocrinol. Diabetes Obes. 2015, 22, 14-20. [CrossRef]

21. Wilhelm, S.; Lipari, M.; Kulik, J.; Kale-Pradhan, P. Teduglutide for the Treatment of Short Bowel Syndrome. Ann. Pharmacother. 2014, 48, 1209-1213. [CrossRef] [PubMed]

22. Dubé, P.E.; Brubaker, P.L. Frontiers in glucagon-like peptide-2: Multiple actions, multiple mediators. Am. J. Physiol. Endocrinol. Metab. 2007, 293, E460-E465. [CrossRef] [PubMed]

23. Wøjdemann, M.; Wettergren, A.; Hartmann, B.; Hilsted, L.; Holst, J. Inhibition of sham feeding-stimulated human gastric acid secretion by glucagon-like peptide-2. J. Clin. Endocrinol. Metab. 1999, 84, 2513-2517. [CrossRef] [PubMed]

24. Wøjdemann, M.; Wettergren, A.; Hartmann, B.; Holst, J. Glucagon-like peptide-2 inhibits centrally induced antral motility in pigs Scand. J. Gastroenterol. 1998, 33, 828-832. [CrossRef] [PubMed]

25. Bremholm, L.; Hornum, M.; Henriksen, B.; Larsen, S.; Holst, J. Glucagon-like peptide-2 increases mesenteric blood flow in humans. Scand. J. Gastroenterol. 2009, 44, 314-319. [CrossRef] [PubMed]

26. Cani, P.; Possemiers, S.; Van de Wiele, T.; Guiot, Y.; Everard, A.; Rottier, O.; Geurts, L.; Naslain, D.; Neyrinck, A.; Lambert, D.; et al Changes in gut microbiota control inflammation in obese mice through a mechanism involving GLP-2-driven improvement of gut permeability. Gut 2009, 58, 1091-1103. [CrossRef] [PubMed]

27. Jeppesen, P.; Gilroy, R.; Pertkiewicz, M.; Allard, J.; Messing, B.; O'Keefe, S. Randomised placebo-controlled trial of teduglutide in reducing parenteral nutrition and/or intravenous fluid requirements in patients with short bowel syndrome. Gut 2011, 60, 902-914. [CrossRef] [PubMed]

28. Jeppesen, P.; Pertkiewicz, M.; Messing, B.; Iyer, K.; Seidner, D.; O’Keefe, S.; Forbes, A.; Heinze, H.; Joelsson, B. Teduglutide reduces need for parenteral support among patients with short bowel syndrome with intestinal failure. Gastroenterology 2012, 143, 1473-1481. [CrossRef] [PubMed]

29. Carter, B.A.; Cohran, V.C.; Cole, C.R.; Corkins, M.R.; Dimmitt, R.A.; Duggan, C.; Hill, S.; Horslen, S.; Lim, J.D.; Mercer, D.F.; et al. Outcomes from a 12-Week, Open-Label, Multicenter Clinical Trial of Teduglutide in Pediatric Short Bowel Syndrome. J. Pediatr. 2017, 181, 102-111.e5. [CrossRef]

30. Kocoshis, S.A.; Merritt, R.J.; Hill, S.; Protheroe, S.; Carter, B.A.; Horslen, S.; Hu, S.; Kaufman, S.S.; Mercer, D.F.; Pakarinen, M.P.; et al. Safety and Efficacy of Teduglutide in Pediatric Patients with Intestinal Failure due to Short Bowel Syndrome: A 24-Week, Phase III Study. JPEN J. Parenter. Enteral Nutr. 2020, 44, 621-631. [CrossRef] [PubMed]

31. Chen, K.; Mu, F.; Xie, J.; Kelkar, S.; Olivier, C.; Signorovitch, J.; Jeppesen, P. Impact of Teduglutide on Quality of Life among Patients with Short Bowel Syndrome and Intestinal Failure. JPEN J. Parenter. Enteral Nutr. 2020, 44, 119-128. [CrossRef] [PubMed]

32. Raghu, V.; Binion, D.; Smith, K. Cost-effectiveness of teduglutide in adult patients with short bowel syndrome: Markov modeling using traditional cost-effectiveness criteria. Am. J. Clin. Nutr. 2020, 111, 141-148. [CrossRef] [PubMed]

33. Jeppesen, P.; Gabe, S.; Seidner, D.; Lee, H.; Olivier, C. Factors Associated with Response to Teduglutide in Patients with Short-Bowel Syndrome and Intestinal Failure. Gastroenterology 2018, 154, 874-885. [CrossRef] [PubMed]

34. Chen, K.; Xie, J.; Tang, W.; Zhao, J.; Jeppesen, P.; Signorovitch, J. Identifying a subpopulation with higher likelihoods of early response to treatment in a heterogeneous rare disease: A post hoc study of response to teduglutide for short bowel syndrome. Ther. Clin. Risk Manag. 2018, 14, 1267-1277. [CrossRef] [PubMed]

35. Chen, K.; Joly, F.; Mu, F.; Kelkar, S.; Olivier, C.; Xie, J.; Seidner, D. Predictors and timing of response to teduglutide in patients with short bowel syndrome dependent on parenteral support. Clin. Nutr. ESPEN 2021, 43, 420-427. [CrossRef] [PubMed]

36. Seidner, D.; Gabe, S.; Lee, H.; Olivier, C.; Jeppesen, P. Enteral Autonomy and Days off Parenteral Support with Teduglutide Treatment for Short Bowel Syndrome in the STEPS Trials. JPEN J. Parenter. Enteral Nutr. 2020, 44, 697-702. [CrossRef] [PubMed]

37. Iyer, K.; Kunecki, M.; Boullata, J.; Fujioka, K.; Joly, F.; Gabe, S.; Pape, U.; Schneider, S.; Virgili Casas, M.; Ziegler, T.; et al Independence from Parenteral Nutrition and Intravenous Fluid Support during Treatment with Teduglutide among Patients with Intestinal Failure Associated with Short Bowel Syndrome. JPEN J. Parenter. Enteral Nutr. 2017, 41, 946-951. [CrossRef]

38. Moher, D.; Liberati, A.; Tetzlaff, J.; Altman, D.G.; Altman, D.; Antes, G.; Atkins, D.; Barbour, V.; Barrowman, N.; Berlin, J.A.; et al. Preferred reporting items for systematic reviews and meta-analyses: The PRISMA statement. PLoS Med. 2009,6 , e1000097. [CrossRef] [PubMed]

39. Sterne, J.A.C.; Savović, J.; Page, M.J.; Elbers, R.G.; Blencowe, N.S.; Boutron, I.; Cates, C.J.; Cheng, H.Y.; Corbett, M.S.; Eldridge, S.M.; et al. RoB 2: A revised tool for assessing risk of bias in randomised trials. BMJ 2019, 366, 14898. [CrossRef] [PubMed]

40. Sterne, J.A.; Hernán, M.A.; Reeves, B.C.; Savović, J.; Berkman, N.D.; Viswanathan, M.; Henry, D.; Altman, D.G.; Ansari, M.T.; Boutron, I.; et al. ROBINS-I: A tool for assessing risk of bias in non-randomised studies of interventions. BMJ 2016, 355 , i4919. [CrossRef]

41. Dersimonian, R.; Laird, N. Meta-Analysis in Clinical Trials. Control Clin. Trials 1986, 7, 177-188. [CrossRef] 
42. Higgins, J.P.T.; Thompson, S.G.; Deeks, J.J.; Altman, D.G. Measuring inconsistency in meta-analyses. Br. Med. J. 2003, 327, 557-560. [CrossRef] [PubMed]

43. Joly, F.; Seguy, D.; Nuzzo, A.; Chambrier, C.; Beau, P.; Poullenot, F.; Thibault, R.; Armengol Debeir, L.; Layec, S.; Boehm, V.; et al Six-month outcomes of teduglutide treatment in adult patients with short bowel syndrome with chronic intestinal failure: A real-world French observational cohort study. Clin. Nutr. 2020, 39, 2856-2862. [CrossRef] [PubMed]

44. Martin, A.; Boehm, V.; Zappa, M.; Billiauws, L.; Bonvalet, F.; Nuzzo, A.; Vilgrain, V.; Joly, F.; Ronot, M. Imaging as predictor of clinical response to teduglutide in adult patients with short bowel syndrome with chronic intestinal failure. Am. J. Clin. Nutr. 2021, 113, 1343-1350. [CrossRef] [PubMed]

45. O'Keefe, S.; Jeppesen, P.; Gilroy, R.; Pertkiewicz, M.; Allard, J.; Messing, B. Safety and efficacy of teduglutide after 52 weeks of treatment in patients with short bowel intestinal failure. Clin. Gastroenterol. Hepatol. 2013, 11, 815-823.e3. [CrossRef] [PubMed]

46. Pevny, S.; Maasberg, S.; Rieger, A.; Karber, M.; Blüthner, E.; Knappe-Drzikova, B.; Thurmann, D.; Büttner, J.; Weylandt, K.; Wiedenmann, B.; et al. Experience with teduglutide treatment for short bowel syndrome in clinical practice. Clin. Nutr. 2019, 38, 1745-1755. [CrossRef] [PubMed]

47. Puello, F.; Wall, E.; Herlitz, J.; Lozano, E.; Semrad, C.; Micic, D. Long-Term Outcomes with Teduglutide from a Single Center. JPEN J. Parenter. Enteral Nutr. 2021, 45, 318-322. [CrossRef]

48. Schoeler, M.; Klag, T.; Wendler, J.; Bernhard, S.; Adolph, M.; Kirschniak, A.; Goetz, M.; Malek, N.; Wehkamp, J. GLP-2 analog teduglutide significantly reduces need for parenteral nutrition and stool frequency in a real-life setting. Therap. Adv. Gastroenterol. 2018, 11, 1756284818793343. [CrossRef]

49. Schwartz, L.; O’Keefe, S.; Fujioka, K.; Gabe, S.; Lamprecht, G.; Pape, U.; Li, B.; Youssef, N.; Jeppesen, P. Long-Term Teduglutide for the Treatment of Patients with Intestinal Failure Associated with Short Bowel Syndrome. Clin. Transl. Gastroenterol. 2016, 7, e142. [CrossRef]

50. Solar, H.; Doeyo, M.; Ortega, M.; De Barrio, S.; Olano, E.; Moreira, E.; Buncuga, M.; Manzur, A.; Crivelli, A.; Gondolesi, G. Postsurgical Intestinal Rehabilitation Using Semisynthetic Glucagon-like Peptide-2 Analogue (sGLP-2) at a Referral Center: Can Patients Achieve Parenteral Nutrition and sGLP-2 Independency? JPEN J. Parenter. Enteral Nutr. 2021, 45, 1072-1082. [CrossRef] [PubMed]

51. Jeppesen, P.B. Short bowel syndrome-Characterisation of an orphan condition with many phenotypes. Expert Opin. Orphan Drugs 2013, 1, 515-525. [CrossRef]

52. Hill, G.L.; Mair, W.S.J.; Goligher, J.C. Impairment of “ileostomy adaptation" in patients after ileal resection. Gut 1974, 15, 982-987. [CrossRef]

53. Jeppesen, P.; Hartmann, B.; Hansen, B.; Thulesen, J.; Holst, J.; Mortensen, P. Impaired meal stimulated glucagon-like peptide 2 response in ileal resected short bowel patients with intestinal failure. Gut 1999, 45, 559-563. [CrossRef]

54. Jeppesen, P.; Hartmann, B.; Thulesen, J.; Hansen, B.; Holst, J.; Poulsen, S.; Mortensen, P. Elevated plasma glucagon-like peptide 1 and 2 concentrations in ileum resected short bowel patients with a preserved colon. Gut 2000, 47,370-376. [CrossRef]

55. Amiot, A.; Messing, B.; Corcos, O.; Panis, Y.; Joly, F. Determinants of home parenteral nutrition dependence and survival of 268 patients with non-malignant short bowel syndrome. Clin. Nutr. 2013, 32, 368-374. [CrossRef]

56. Messing, B.; Crenn, P.; Beau, P.; Boutron-Ruault, M.; Rambaud, J.; Matuchansky, C. Long-term survival and parenteral nutrition dependence in adult patients with the short bowel syndrome. Gastroenterology 1999, 117, 1043-1050. [CrossRef]

57. Carbonnel, F.; Cosnes, J.; Chevret, S.; Beaugerie, L.; Ngô, Y.; Malafosse, M.; Parc, R.; Le Quintrec, Y.; Gendre, J. The role of anatomic factors in nutritional autonomy after extensive small bowel resection. JPEN J. Parenter. Enteral Nutr. 1996, 20, 275-280. [CrossRef] 